\title{
Evaluation of Water Resistance and Diffusion Properties of Paint Materials
}

\begin{abstract}
J. Drchalová, J. Poděbradská, J. Maděra, R. Černý
A simple method is presented for evaluating the water-proofness quality of paints on lining materials. The method is based on measuring the integral capillarity in dependence on time, and then comparing this value to the value determined for the basic lining material. Measurements of the effective water vapor permeability then provide information on the risk of condensation which may increase after applying the paint. A practical application of the method is performed with four Karlocolor paints on glass concrete substrates. All the Karlocolor paints are found to be very effective materials for driven rain protection. The diffusion properties of all the paints are found to be excellent.
\end{abstract}

Keywords: water-proofness, diffusion coefficient, paints.

\section{Introduction}

The water-proofness quality of paint materials can be evaluated by various methods. A first look into the evaluation can provide information about two material parameters characteristic of moisture transport in porous materials, namely the diffusivity of liquid moisture $\kappa$ and water vapor diffusivity $D$. However, these parameters may not be known because it is particularly difficult to measure $\kappa$ for materials containing small pores only, and in addition neither $\kappa$ nor $D$ themselves tell us anything about the influence of paint thickness or about the properties of the contact surface between the paint and the substrate. Therefore, direct testing of the paint-substrate system is more desirable.

One of the physical quantities characterizing the behavior of capillary-porous materials in contact with water is the height of capillary rise, i.e., the maximum height $h_{\max }$ of the water column in the material above the main water level. However, measurements of $h_{\max }$ are very time consuming and, in the main, inaccurate [1].

A more suitable quantity for evaluating quality of water-proofness is the capillarity $C$, defined by the relation

$$
C=\frac{1}{S} \frac{\mathrm{d} m}{\mathrm{~d} t},
$$

where $S$ is the surface of the specimen which is in contact with water, $m$ is the mass of the moistened specimen, and $t$ is the time. As a matter of fact, the capillarity defined by (1) is identical with the water flux in the material.

The value of $C$ is an instantaneous quantity which does not provide any information on the history of the moistening process. Therefore, it appears reasonable to define the integral capillarity $C_{i n t}$ (see, e.g., [2-4])

$$
C_{i n t}(t)=\int_{0}^{t} C(\tau) \mathrm{d} \tau=\frac{m(t)-m_{d}}{S},
$$

where $m$ is the mass of the moist specimen, and $m_{d}$ is the mass of the dried specimen.

Integral capillarity can express not only the absolute amount of water in the specimen but also the time history of the moistening process, which is particularly useful in comparing the effectiveness of various paints on a specified substrate. Therefore, we employ the $C_{i n t}(\tau)$ function as the main parameter in evaluating the water-proofness of paint materials throughout this paper.

Measuring the water vapor diffusion properties of paint-substrate systems can provide useful complementary information on water-repellent paints. Paints applied on external linings should protect the underlying layers from water penetration but, on the other hand, they should not oppose water transport from the interior to the exterior in order to avoid the formation of condensing zones in walls.

Therefore, the effective diffusion coefficient of the paint-substrate system is the second important parameter in evaluating the quality of the paint materials in this paper.

\section{Materials and samples}

In our experimental work, we studied the hygric properties of selected Karlocolor masonry paints on glass concrete substrates.

The glass concrete was produced by VUSH, a. s., Brno. The following basic proof the samples were determined: density $1800 \mathrm{~kg} / \mathrm{m}^{3}$, saturation water content $13.5 \% \mathrm{~kg} / \mathrm{kg}$.

The following Karlocolor masonry paints (producer: Karlomix, s. r. o., Czech Republic) were tested: 10-001, 11-001, 20-001, 30-001. Karlocolor 10-001 is a disperse acrylate paint consisting of styrene-acrylate, quartz sand, inorganic pigments, some special additives and water. Karlocolor 11-001 has a similar composition as 10-001 but contains pure acrylate instead of styrene-acrylate. Karlocolor 20-001 is a silicon paint which consists of silicon emulsion, acrylate dispersion, quartz sand, inorganic pigments, some special additives and water. Karlocolor 30-001 is a silicate paint consisting of potassium water glass, acrylate dispersion, quartz sand, inorganic pigments, some special additives and water.

\section{Measuring integral capillarity}

In order to measure integral capillarity we used samples of substrate materials that were cylindrical in shape, with a diameter of $110 \mathrm{~mm}$ and a height of $10 \mathrm{~mm}$. The lateral area of all specimens was water- and vaporproof insulated by epoxy resin, and the specimens were placed with their face side into the vessel with water on a soft sponge, so that the upper side of the sponge was just on the water level. The mass 
of the specimens absorbing water was then determined at specified time intervals, and the experiment was stopped after a period of five days. During the experiment, the level of water in the vessel was kept constant. Finally, the dependence of integral capillarity on time was determined according to the definition formula given above.

The integral capillarities $C_{\text {int }}$ of the paint-substrate systems described above are shown in Figs. 1a-d, where various time scales were applied for better clarity. Figs. 2a-d show details of the differences between particular paints in the same time scales.

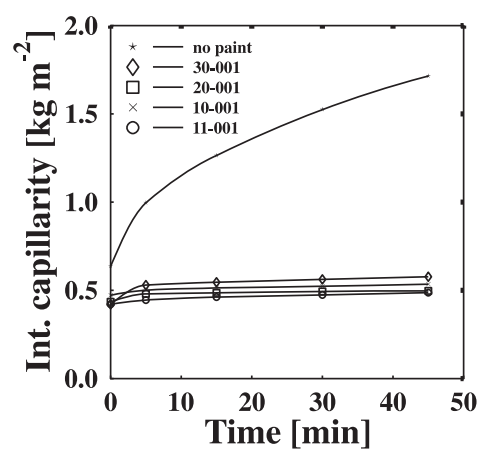

Fig. 1a: Integral capillarity of paint-glass concrete systems for $t \in[0,45 \mathrm{~min}]$

Fig. 1a shows that all applied paints exhibited very good water repellent properties during short term water exposure.

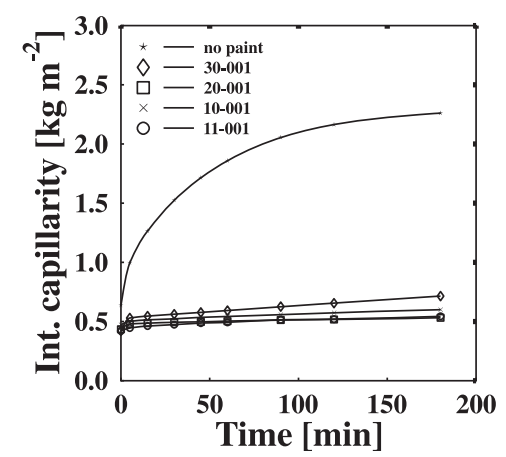

Fig. 1b: Integral capillarity of paint-glass concrete systems for $t \in[0,180 \mathrm{~min}]$

The integral capillarity after 45 minutes was approximately equal to $25 \%$ of its value for the basic material without surface treatment. The same situation was observed for 180 minutes'

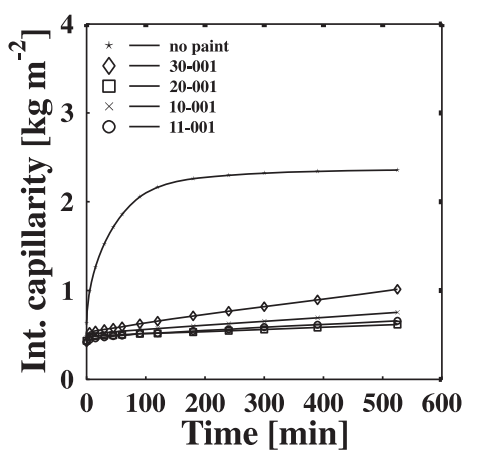

Fig. 1c: Integral capillarity of paint-glass concrete systems for $t \in[0,540 \mathrm{~min}]$ exposure (Fig. 1b), and even after 9 hours the value of integral capillarity was still about one third of the value for the basic material (Fig. 1c). Fig. 1d shows that the paints lost their wa-

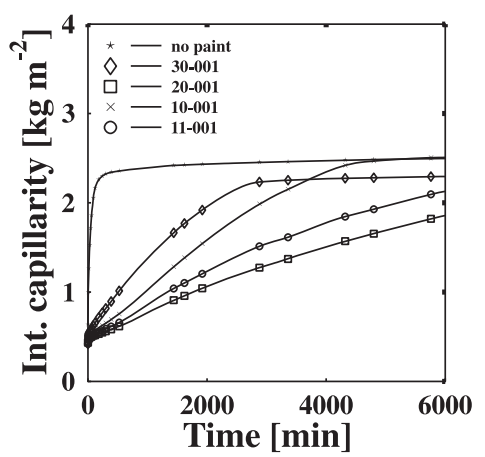

Fig. 1d: Integral capillarity of paint-glass concrete systems for $t \in[0,6000 \mathrm{~min}]$

ter protective function after water exposure greater than 70 hours. This is a very good result, because building facades are only very exceptionally exposed to such long water exposure, for instance due to wind driven rain.

The detailed Figs. 2a-d show that the best water repellent properties among the applied paints were exhibited by the

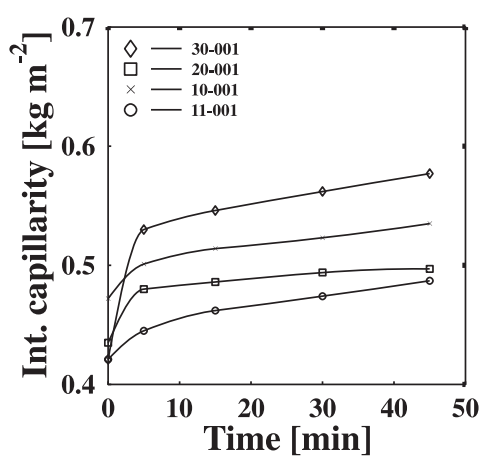

Fig. 2a: Integral capillarity of paint-glass concrete systems for $t \in[0,45 \mathrm{~min}]$, a detail

11-001 and 20-001 paints, i.e. those based on pure acrylate and silicon emulsion. The worst results were obtained for the

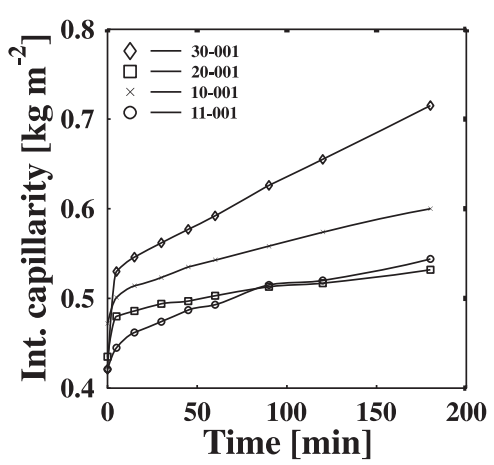

Fig. 2b: Integral capillarity of paint-glass concrete systems for $t \in[0,180 \mathrm{~min}]$, a detail

silicate based paint 30-001. However, it should be noted that this is really only a relative result compared to the other paints, and that the water repellent properties of 30-001 paint are still satisfactory. 


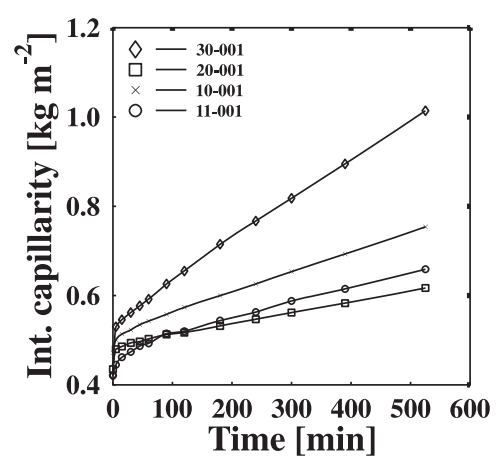

Fig. 2c: Integral capillarity of paint-glass concrete systems for $t \in[0,540 \mathrm{~min}]$, a detail

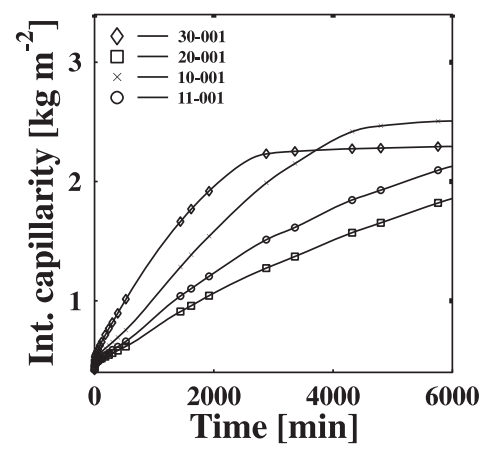

Fig. 2d: Integral capillarity of paint-glass concrete systems for $t \in[0,6000 \mathrm{~min}]$, a detail

\section{Measuring the effective diffusion coefficient of water vapor}

When evaluating water vapor transport properties, we preferred diffusion coefficient $D$ defined as

$$
j=-D \operatorname{grad} \rho_{\mathrm{c}},
$$

rather than diffusion permeability $\delta$, which is defined as follows:

$$
j=-\delta \operatorname{grad} p_{v} .
$$

In Eqs. (3) and (4), $j$ is the flux of water vapor, $\rho_{c}$ is the mass of water vapor per unit volume of the porous material, and $p_{v}$ is the partial pressure of water vapor.

We point out that under isothermal conditions, the following relation between diffusion coefficient and permeability is valid:

$$
D=\delta \frac{R T}{M} .
$$

Some other coefficients widely employed in building physics, namely vapor diffusion resistance number $\mu$, water vapor resistance $Z$ and equivalent air layer thickness $S_{D}$ are defined as follows:

$$
\begin{aligned}
& \mu=\frac{D_{a}}{D} \\
& Z=\frac{d}{\delta} \\
& S_{D}=\frac{D_{a}}{D} \cdot d,
\end{aligned}
$$

where $D_{a}$ is the diffusion coefficient of water vapor in air, and $d$ is the thickness of the specimen of porous material.

For measuring the effective diffusion coefficient of water vapor $D$ we chose a steady-state method that is commonly used for experimental work on other materials. The measuring apparatus consists of two airtight glass chambers separated by the sample of measured material, which is typically board-type. In the first chamber a state near to $100 \%$ relative humidity is maintained (achieved with the help of a cup of water), while in the second chamber there is a state close to $0 \%$ relative humidity (set up using some absorption material, such as silica gel). After a certain time, measurement is interrupted, and the changes in the mass of water in the cup, $\Delta m_{\mathrm{w}}$, and of the silica gel, $\Delta m_{\mathrm{a}}$, during the chosen time interval $[0, \tau]$ are determined. If $\left|\Delta m_{\mathrm{w}}\right|=\left|\Delta m_{\mathrm{a}}\right|$, i.e., if a steady state is established within the measuring system, the experiment is terminated. Otherwise, the measurement continues in the same way as before. The experiment is carried out under isothermal conditions.

The diffusion coefficient at temperature $T$ can be calculated using the following formula:

$$
D=\frac{\Delta m_{\mathrm{W}} R d}{S \tau M \cdot T^{C-1} \cdot 10^{-\frac{A}{T}+B}},
$$

where $d$ is the thickness of the board-type specimen, $M$ is the molar mass of water vapor, $R$ is the universal gas constant, $A, B, C$ are the constants in the empirical formula describing the dependence of the saturated water vapor pressure on temperature $p_{\mathrm{v}, \mathrm{s}}$,

$$
p_{v, s}=T^{C} \cdot 10^{-\frac{A}{T}+B},
$$

$A=2900 \mathrm{~K}, B=24.738, C=-4.65$.

The material specimens for measuring the difffusion properties of the paintsubstrate systems were prepared in the same way as for the measurements of integral capillarity, and their dimensions were also the same.

Table 1: Effective diffusion parameters of selected paint-glass concrete systems

\begin{tabular}{|c|c|c|c|c|c|c|}
\hline Paint & $d(\mathrm{~m})$ & $D\left(\mathrm{~m}^{2} \mathrm{~s}^{-1}\right)$ & $\delta(\mathrm{s})$ & $\mu(-)$ & $Z\left(\mathrm{~ms}^{-1}\right)$ & $S_{\mathrm{D}}(\mathrm{m})$ \\
\hline none & $9.5 \cdot 10^{-3}$ & $1.34 \cdot 10^{-6}$ & $0.99 \cdot 10^{-11}$ & 17.2 & $0.96 \cdot 10^{9}$ & 0.16 \\
\hline $10-001$ & $12.2 \cdot 10^{-3}$ & $1.47 \cdot 10^{-6}$ & $1.08 \cdot 10^{-11}$ & 15.7 & $1.13 \cdot 10^{9}$ & 0.19 \\
\hline $11-001$ & $11.6 \cdot 10^{-3}$ & $1.29 \cdot 10^{-6}$ & $0.94 \cdot 10^{-11}$ & 17.9 & $1.23 \cdot 10^{9}$ & 0.21 \\
\hline $20-001$ & $12.9 \cdot 10^{-3}$ & $1.26 \cdot 10^{-6}$ & $0.91 \cdot 10^{-11}$ & 18.3 & $1.41 \cdot 10^{9}$ & 0.24 \\
\hline $30-001$ & $12.1 \cdot 10^{-3}$ & $1.48 \cdot 10^{-6}$ & $1.07 \cdot 10^{-11}$ & 15.5 & $1.12 \cdot 10^{9}$ & 0.19 \\
\hline
\end{tabular}


The effective diffusion parameters of the analyzed paint-glass concrete systems are summarized in Table 1. The properties of all paints analyzed were found to be excellent for systems of this kind. The differences in the diffusion properties of the systems with the particular paints from the basic material were less than $10 \%$ which is within the errorbar of the experimental method. Therefore, within this measurable range no differences from the basic material were observed.

\section{Conclusions}

In this paper, we analyzed several paint-glass concrete systems from the point of view of their water repellent and diffusion properties. All the Karlocolor paints were found to be very effective water repellent materials, because in short term water exposure they decreased the integral capillarity of the system to about $25 \%$ of its value for the basic material, and retained their water repellent function for more than 70 hours, which is quite sufficient for wind driven rain protection. The diffusion properties of all paints were found to be excellent. The decrease in diffusion permeability due to the paint application was within the errorbar of the applied measuring method, i.e., lower than $10 \%$.

\section{Acknowledgement}

This research was supported by the Ministry of Education of the Czech Republic, under contracts

No. CEZ: J04/98:210000003 and CEZ: J04/98:210000004.

\section{References}

[1] Mrlík, F.: Moisture-Induced Problems of Building Materials and Constructions (in Slovak). Alfa, Bratislava, 1985
[2] Hansen, K. K. and Bunch-Nielsen, T.: Capillary rise of water in insulating materials and in gravel and stone, Part I. Mineral wool and expanded polystyrene. Proc. of the $3^{\text {rd }}$ Symp. Building Physics in the Nordic Countries, Vol. 2., Copenhagen, 1993, pp. 761-768

[3] Hansen, K. K. and Bunch-Nielsen, T.: Capillary rise of water in insulating materials and in gravel and stone, Part II. Product of lightweight expanded clay aggregates. Proc. of the $3^{\text {rd }}$ Symp. Building Physics in the Nordic Countries, Vol. 2., Copenhagen, 1993, pp. 769-776

[4] Hansen, K. K. and Bunch-Nielsen, T.: Capillary rise of water in insulating materials and in gravel and stone, Part III. Gravel and stone. Proc. of the $3^{\text {rd }}$ Symp. Building Physics in the Nordic Countries, Vol. 2., Copenhagen, 1993, pp. 777-782

RNDr. Jaroslava Drchalová, CSc.

Department of Physics

phone.: +420224354586

e-mail:drchalov@fsv.cvut.cz

Prof. Ing. Robert Černý, DrSc.,

Ing. Jitka Poděbradská,

Ing. Jiří Maděra,

Department of Structural Mechanics

phone.: +420224354429

e-mail: cernyr@fsv.cvut.cz

Czech Technical University in Prague

Faculty of Civil Engineering

Thákurova 7, 16629 Praha 6, Czech Republic 